\title{
HISTORIA Y ANSIEDADES DE LA CRÍTICA DE LOS CINES AFRICANOS A TRAVÉS DE LA PERSONA Y LA OBRA DE MED HONDO
}

\author{
History and anxieties of African Cinema criticism through the life and \\ work of Med Hondo
}

\author{
Beatriz LEAL Riesco \\ Investigadora independiente \\ leal78@gmail.com
}

Fecha de recepción: 1-III-2014

Fecha de aceptación: 19-V-2014

\begin{abstract}
Resumen: Con la distancia que nos da el paso de los años y a la luz de la transformación contemporánea de los paradigmas de análisis crítico-teóricos de los estudios de los cines de África, nos hallamos en un momento idóneo para acercarnos a los discursos que han ido surgiendo en relación a la persona y la obra del director mauritano Med Hondo. La historia de la crítica, la teoría y la historia real de los cines africanos se entremezclan en la imagen-estigma de director rebelde, radical y marxista que lo acompańa desde su exitosa primera película Soleil $\hat{O}$ (1969) y que no lo ha abandonado hasta la actualidad. Examinar las posturas y consideraciones sobre el director en publicaciones académicas sobre los cines africanos revela las ansiedades y condicionamientos materialistas de críticos y teóricos especializados, y nos llevará a descubrir las relaciones determinantes que el discurso académico ha tenido sobre la difusión, comprensión y recepción de su obra.
\end{abstract}

Palabras clave: Med Hondo; crítica y teoría cinematográfica; estudios africanos; historia; recepción.

AвSTRACT: With the distance permitted by the passage of years and the perspectives opened up by the contemporary transformation of critical-theoretical paradigms in African cinema studies, we have arrived at an ideal moment for approaching the discourses that have 
arisen around the Mauritanian director Med Hondo. The history of criticism, theory, and the actual history of African cinemas are interwoven in the image/stigma of the rebellious and radical Marxist director, which has accompanied Hondo since his successful first film Soleil $\hat{O}$ (1969) and has clung to him up to the present day. An examination of the positions taken with respect to this director in academic publications relating to African cinemas reveals the anxieties and materialist provenance of specialized critics and theorists, and leads one to a recognition of the decisive effect that academic discourse has exercised on the diffusion, understanding, and reception of his work.

Keywords: Med Hondo; cinema theory and criticism; African studies; history; reception.

SUMARIO: 1. Introducción. 2. Una historia de errores y desencuentros. 3. Una historia crítica de los estudios de cine africanos. 4. Conclusión. 5. Filmografía de Med Hondo. 6. Bibliografía.

\section{INTRODUCCIÓN}

I would like outsiders to engage me in a meaningful dialogue, to have a better understanding of my work and philosophy ${ }^{1}$.

En una de las entrevistas recogidas en Questioning African Cinema. Conversations with Filmmakers, Med Hondo respondía animando al diálogo a la observación del historiador, teórico y profesor de cine Nwachukw Frank Ukadike sobre la lamentable incomprensión que se tiene de su filosofía y sus películas. En el párrafo que cierra esta cita, haciendo uso de un estilo provocador a la par que reflexivo, Hondo aprovechaba la publicación de la entrevista en una editorial académica estadounidense para subrayar la importancia de mejorar el entendimiento mutuo y las relaciones económicas entre africanos y norteamericanos, a partir de un conocimiento adecuado de la historia y el cine. Esta búsqueda de nuevos horizontes se producía como reacción a la censura política y económica que desde Francia habían sufrido sus películas irreverentes y críticas producidas en los márgenes de la industria del cine comercial. Centradas en la política colonial y postcolonial francesa tanto en territorio nacional como africano, sus filmes no habían dejado indiferentes a los protectores de la Françafrique, quienes habían empleado mecanismos diversos para evitar su difusión. Poco antes, en la misma conversación, el autor utilizaba un tono más categórico y universal:

The consciousness guides me not only to speak the truth but also to remain part of the truth. I have never called myself a revolutionary, or a Marxist, an activist maybe, but

En N. Frank Ukadike (ed.), Questioning African Cinema. Conversations with Filmmakers, Minneapolis, University of Minnesota Press, 2002. p. 71. 
for some people it is easier to put me in a box to marginalize me, to avoid engaging in debates with me, and to avoid seeing or accepting the reality I present ${ }^{2}$.

En ambos casos, Med Hondo propone entablar diálogo con aquellos que lo tachan de marxista y revolucionario, epítetos cuyo objetivo ha sido el de desacreditarlo enfatizando su dimensión política. Tales atributos se han hecho extensivos a sus obras, rebajando o simplificando su estatuto artístico e induciendo perniciosos efectos a la hora de la distribución, exhibición y recepción de las mismas. Como desafío a la autoridad de estas etiquetas, Med Hondo admite su responsabilidad como sujeto histórico, a través de sus películas y de su propia vida, más allá de su faceta de director de cine. Para ello, se ofrece a explicar en detalle cuál es su filosofía, en la que la conciencia y la búsqueda de la verdad son valores guías. A día de hoy, su provocación no ha tenido el eco esperado.

Cierto es que, en las declaraciones recogidas por Ukadike, el director no especificaba a quién se refería con estas críticas. Sí, en cambio, se paraba a detallar las desavenencias surgidas con productores y responsables de la administración, los cuales habían impedido o detenido la realización y exhibición de algunos de sus filmes. Más adelante en la misma entrevista, Med Hondo será más claro, lanzando una llamada a la rigurosidad y responsabilidad del análisis crítico-teórico, en paralelo a la del artista:

Each filmmaker is responsible for his work, and people who are critics, essayists, philosophers, and teachers have to analyze more profoundly the dilemmas facing the filmmakers ${ }^{3}$.

Partiendo de sus palabras, me centraré en este artículo en una parte de la crítica cinematográfica africana la cual, durante años, ha ido forjando lugares comunes sobre su persona y su obra sin la rigurosidad analítica requerida, explicitando las derivas ideológicas y subordinación a las modas y exigencias materiales de la Academia. De este modo, pretendo demostrar la responsabilidad de los académicos en la construcción de un corpus analítico y teórico sobre los cines africanos así como sus efectos en la recepción de las películas y directores considerados. Frente a otras cinematografías, en el acto de recepción de las películas africanas la aceptación por parte de la Academia tiene una importancia desmesurada. Debido a la precaria difusión comercial de estos filmes, sus proyecciones se circunscriben en gran medida a aulas universitarias y a festivales de cine. $\mathrm{Su}$ audiencia es, por tanto, educada e instruida, caracterizada por acercarse a la obra bien después de la lectura crítica, bien a través de un mediador informado: un profesor universitario o especialista en un festival, dos roles que, en muchos casos, se solapan. En

2 En N. Frank Ukadike (ed.), Questioning African Cinema. Conversations with Filmmakers, Minneapolis, University of Minnesota Press, 2002. p. 65.

3 Ibid., p. 68. 
este contexto de distribución, exhibición y recepción mediado, las opiniones de la crítica se convierten en camisas de fuerza, limitando el alcance del acceso a las películas. En el caso particular de Med Hondo, estos efectos se han revelado negativos.

Otro hecho ha sido determinante en la escasa distribución de los filmes de Hondo, del cual el autor es directamente responsable. Escarmentado por la experiencia de exhibición de su primer largometraje Soleil Ô (1969) en los EEUU y Canadá, de cuyas numerosas proyecciones no vio durante años ni un solo céntimo, Med Hondo se ha negado a distribuir sus películas por precios irrisorios o de manera gratuita, una realidad habitual para buena parte de directores africanos incluso en nuestros días. Al oponerse asimismo a publicar sus películas en VHS para evitar la piratería (postura compartida con Sembène Ousmane y Kwah Ansah) ha impedido su difusión, provocando que otros artistas del continente hayan, a la larga, merecido una atención comparativamente desproporcionada.

Hoy más que nunca, es precisa una ruptura en el discurso crítico y en las actitudes de recepción de Med Hondo pues la marginación sufrida a causa de sus ideas, su manera de trabajar y su radicalidad estética y formal nos ofrecen una historia adulterada del cine en África que urge corrección. Serán esos «outsiders» convocados por el director -críticos, teóricos y pensadores que se opongan a los discursos preestablecidos, en la línea de los reunidos en la reciente publicación editada por Ukadike Critical Approaches to African Cinema Discourse 4 - los que lo sitúen en el lugar que merece en la historia de los cines africanos y de la cinematografía universal.

\section{UNA HISTORIA DE ERRORES Y DESENCUENTROS}

Cineasta, productor, actor y actor de doblaje, Mohamed Abid Medoun Hondo (conocido popularmente como Med Hondo) nació en 1936 en Ain Ouled Beri Mathar, en la región Atar de Mauritania. De padre senegalés y madre local, su abuelo materno era un esclavo, realidad que impresionaría al nieto y que junto a las numerosas historias de revueltas escuchadas en su infancia, marcarían la trayectoria combativa del futuro artista. No en vano es considerado como uno de los defensores más congruentes y de mayor talento de un cine revolucionario africano y negro legítimo, tanto por los temas como por su forma y técnica. Autodidacta cinematográfico, su filmografía es pieza insoslayable del Tercer Cine, movimiento nacido a mediados del siglo pasado con el fin de emplear el medio cinematográfico como herramienta para hacer frente a los desafíos de las sociedades contemporáneas y cambiar la escritura de la historia. Sus filmes abiertamente de oposición, alineados con la experiencia de los desfavorecidos, eluden paralelismos y

N. Frank Ukadike (ed.), Critical Approaches to African Cinema Discourse, Plymouth, Lexington Books, 2014. 
similitudes con el cine popular africano del continente o la diáspora por su temática y, especialmente, por su forma, mensaje y calidad técnica, lo cual ha confundido a algunos críticos.

La preocupación dominante de Hondo, desde su primer largometraje Soleil Ô (1969) pasando por Les Bicots Nègres: Vos Voisins (1973) hasta West Indies: Les Nègres Marrons de la Liberté (1979) serán las duras condiciones de vida de los trabajadores emigrantes en Francia, adelantándose en décadas a documentales y películas de ficción similares. La esclavitud, el colonialismo y sus efectos contemporáneos en África, Europa y el Caribe se representan en cada una de los filmes citados a través de las relaciones entre los emigrantes con los ciudadanos franceses y sus instituciones. El fuerte anclaje histórico de sus narrativas, la cita de escritores voceros del panafricanismo, su mensaje humanista y anticolonial, la audacia y irreverencia en el empleo de la técnica, la narración y los códigos cinematográficos (desde la imagen al sonido sin olvidarse de la puesta en escena y la actuación), le convierten en defensor acérrimo de un lenguaje renovado y liberador tanto por los temas elegidos como por su tratamiento. En el actual clima de racismo y aversión europea a la entrada, permanencia e integración de emigrantes extracomunitarios, las películas de Med Hondo de mediados de los años 70 se han de entender proféticas, y su labor de recuperación de los sujetos negros dentro de la Historia universal una de la piedras de toque de todo su quehacer. Su experimentación técnica y formal, un reto para los estudiosos, demuestran su respeto y rigurosidad en el uso del lenguaje cinematográfico. Si el cine de África ha de ser valorado, ha de serlo a raíz de un estudio igualitario con las producciones de otras cinematografías. Distinguido por su ansia de investigar y de superarse a la búsqueda del estilo y forma adecuados para transmitir su mensaje en cada nuevo filme, su producción no tiene paralelo en África.

Crecido en Mauritania y formado en la escuela de hostelería en Marruecos, el joven Med Hondo se traslada pronto a Francia con la intención de trabajar de chef. La pasión por el teatro y una tenue, por aquel entonces, conciencia de la escasa representación de los negros en la escena teatral local, le impulsan a fundar su propia compañía: Griot-Shango (inicialmente Shango, tomando el nombre del dios Yoruba del trueno), con la que montaría en París piezas de africanos y afro-americanos. Las dificultades de financiación, el escaso interés del público y el racismo estructural le decepcionaría de tal modo que se lanzaría al mundo del cine: "... je décidai de faire du cinéma parce que (...) c'est un art que laisse des traces $\aleph^{5}$. $\mathrm{Al}$ aprendizaje autodidacta del cine como actor de reparto y asistente de director se unirá una conciencia política más madura, tras la lectura atenta de escritores africanos como el argelino Kateb Yacine, el senegalés Cheick Anta Diop y los imprescindibles Aimé Cesaire y Frantz Fanon de Martinica, a los que pronto

En Ibrahima Signaté. Med Hondo. Un cinéaste rebelle, París y Dakar, Présence africaine, 1994. pp. 19-20. 
se unirían Marx, Nasser, Nkrumah o Mao. En la fecha temprana de 1966 realizaría el cortometraje Ballade aux sources sobre la historia de un emigrante que regresa desilusionado a África tras vivir en unas condiciones terribles en Francia, aunque las referencias a los escritores y pensadores anotados serán más visibles en su primer largometraje Soleil $\hat{O}$, película que recibió elogios unánimes de la crítica en Cannes. Definida por el propio director como «l'histoire de la prise de conscience politique d'un inmigré africain» ${ }^{6}$ y la más fanoniana de sus obras ${ }^{7}$, es notable su experimentación formal y su clara ideología marxista y anticolonial. Rodada los fines de semana durante dos ańos con un reparto de amigos, en su presentación en Cannes en 1970 los críticos occidentales, conocedores de la residencia parisina del director, sugerirían diligentemente la experimentación y libertad formal de la Nouvelle Vague como inspiración para su narrativa zigzagueante, su inclusión de imágenes de animación, sus escenas filmadas con técnicas neorrelistas y su cruda puesta en escena teatral. En realidad, en las decisiones formales de Hondo poco tenían que ver la gramática y sintaxis cinematográficas de los jóvenes turcos de la revista Cahiers. Tal y como ha subrayado en más de una ocasión Med Hondo, sus resoluciones beben directamente de la tradición teatral y oral africana, a la que se une la educación occidental de manera tenue. Como apuntan Murphy y Williams: «... it was the African tradition of digressive and multi-layered narrative which was the formative influence» ${ }^{8}$. Este error flagrante demuestra el desconocimiento de la crítica occidental de tradiciones y expresiones artísticas africanas, actitud motivada por la apropiación de sujetos, tradiciones e historias ajenos para la historia del cine occidental sin alterar la narrativa preexistente. Los malentendidos surgieron desde su primera realización cinematográfica y no le han abandonado hasta el día de hoy.

Tras West Indies: Les Nègres Marrons de la Liberté (1979) Med Hondo necesitará siete años de tribulaciones ${ }^{9}$ para realizar su obra más conocida y difundida: la épica histórica Sarraounia (1986), ganadora del Étalon de Yennenga de FESPACO un año después. Esta película levantaría tantas ampollas sobre la actuación asesina de las tropas coloniales francesas en África inmediatamente después de la Conferencia de Berlín (1884-85) que sufriría una censura económica que dejaría al director con deudas impagables ${ }^{10}$. Lo

$6 \quad$ En Ibrahima Signaté. Med Hondo. Un cinéaste rebelle, París y Dakar, Présence africaine, 1994. p. 20.

7 Para un análisis en profundidad de la película en términos fanonianos, véase el capítulo de Murphy y Williams dedicado a Med Hondo en: David Murphy y Patrick Williams, Postcolonial African Cinema. Ten directors, Manchester, Manchester University Press, 2007. Pp. 71-90.

8 En David Murphy y Patrick Williams, Postcolonial African Cinema. Ten directors, Manchester, Manchester University Press, 2007. p. 76.

9 Cuando se estaba a punto de empezar a rodar en Níger, el gobierno retiró el permiso (probablemente por presiones del gobierno francés) y tuvo que recurrir a la ayuda del líder socialista de Burkina Faso Thomas Sankara para seguir adelante con el proyecto.

10 Les Filmes du Losange, su distribuidora, había prometido proyectar la película en 14 salas y sólo lo hizo en 5 , además de darle escasa publicidad. 
mismo sucedería con sus películas de los años 90: Lumière Noire (1994) y Watani, un monde sans mal (1998). En el caso de Lumière Noire, el primer polar africano político, se le impedirían rodar las escenas de la expulsión de los emigrantes en aeropuertos franceses porque "c'est une sale histoire que raconte le film». En realidad, la escena estaba basada en un hecho verídico de expulsión de cien malienses en un vuelo chárter ${ }^{11}$. En el caso de Watani, se adujo un alto grado de violencia de las imágenes, lo cual unido a la calificación de película para mayores de edad, limitaba su recaudación en salas resultando en una censura económica de facto. Además de sus documentales, su última ficción ha sido Fatima, l'Algérienne de Dakar (2004), con guión de Med Hondo y del crítico de cine y fundador del Festival de cine de Cartago, el tunecino Tahar Cheriaa. En palabras del crítico Olivier Barlet, su tema central es la «confiscación de las independencias africanas por las élites corruptas» ${ }^{12}$.

Se podría argüir que hay cineastas adelantados a su tiempo, que no evitan asaltar los problemas más lacerantes de las sociedades de las que forman parte sirviéndose de la experimentación de la forma y renovando el lenguaje y el medio artístico en el que trabajan. Insignes son los casos en los que el público los reconoce con retraso de décadas, viviendo una tardía o póstuma época dorada. Esta realidad es, sin embargo, inexcusable en lo que atañe a la labor de críticos y teóricos especializados. En el caso de Med Hondo, varias paradojas y contradicciones giran alrededor de sus obras y su persona, lo que dificultan su cómoda incorporación en la historia canónica de los cines en África. Su figura es contradictoria y esquiva, como lo demuestran varios malentendidos y afirmaciones de cariz ideológico.

En primer lugar, pocos han podido ver y revisitar sus películas a lo largo del tiempo al haber sido censuradas o descartadas por diversas instancias (políticas, críticas, económicas). El efecto directo ha sido que muchas filmotecas o bibliotecas universitarias no las incluyan en sus catálogos, y que las retrospectivas de su obra hayan sido numéricamente inferiores a las de otros directores africanos fundadores. Paradójicamente, citarlas es obligación ineludible tanto por la variedad de los temas afrontados como por su tratamiento formal original. Al no poder ser analizadas directamente, se entra en una espiral de citas y comentarios superficiales.

En segundo lugar, a pesar de incluirse reiteradamente entre los cinco mejores directores de los inicios de los cines africanos, yuxtapuesto a los senegaleses Sembène Ousman y Djibril Diop Mambety y a los malienses Souleymane Cissé y Cheick Oumar

11 En Ibrahima Singaté, Med Hondo. Un cinéaste rebelle, París y Dakar, Présence africaine, 1994. p. 47.

12 Crítica de Olivier Barlet a la película Fatima, l'Algérienne de Dakar en Africultures (05/07/2004): <http://www.africultures.com/php/?nav=article\&no=3453\#sthash.1oEZxC9v.dpuf> (última consulta: 30/04/2014). 
Sissoko, su ubicación siempre ha sido marginal y de oposición, incluso de indeterminación. La frivolidad de los análisis que lo acompañan merecen ser estudiados, lo que nos ayudará a comprender la historia de la crítica y teoría de los cines africanos.

Como hemos visto, a pesar de habérsele alineado con la Nouvelle Vague tachándolo de «occidental» en su estilo, Hondo ha venido adaptando concienzudamente obras y pensadores africanos durante toda su carrera. Es curioso que esto suceda mientras que el senegalés Djibril Diop Mambety, uno de los directores indiscutiblemente «más africanos», recurría a la tradición occidental tanto en temas como en obras de referencia ${ }^{13}$. Med Hondo, además de montar obras de teatro de escritores afroamericanos y africanos, convoca habitualmente a intelectuales y escritores africanos en sus películas (Sarraounia, por ejemplo, es la adaptación de una novela homónima del escritor Abdoulaye Mamani de Níger) y ha sido uno de los más fervientes defensores de una alianza de países africanos en la línea del Tercer Cine y el Pan-africanismo, siendo miembro activo de la firma de The Algiers Charter of African Cinema adoptada de manera unánime el 18 de enero de 1975 y aprobada dentro del segundo congreso de la FEPACI (Federación Panafricana de Cineastas). Hemos anotado también que el estilo de Med Hondo bebe de la tradición oral africana y su crítica política de izquierdas se forjó dentro de su experiencia familiar y leyendo a pensadores del continente. En esta línea comenta a Ukadike:

I believe I have something to give back to African people. I am a Mauritanian, but first of all, I am an African. My ancestors (...) in the performance of their duty, faced danger and experienced all sorts of insults and exploitation when they fought to liberate us. I cannot betray them. I consider myself to be, along with them, part of the entire history of Africa ${ }^{14}$.

A pesar de todo ello, Hondo se ha enfrentado a críticas de sus películas como «occidentales», lo que se ha extendido a su persona negándole el ser «auténticamente africano». En este sentido, David Murphy reflexiona pertinentemente sobre la obra de Sembène y Hondo cuestionando el concepto obsesivo de «autenticidad» que acompaña a los cines africanos desde la crítica occidental:

What room do such views leave for the films of Ousmane Sembene and Med Hondo which sought to produce a radical critique of independent African societies? The artic-

13 La valoración de Djibril Diop Mambety viene ligada a un discurso nativista-humanista-poético generalizado sobre los cines africanos que favorece las películas realizadas en el continente con un mensaje abierto y poéticamente ambiguo frente a las que se ocupan de problemáticas del encuentro de África con Occidente. Esta misma razón ha provocado que Afrique sur Seine (1957) haya sido desestimada frente a Borom Sarret (1996) de Sembène Ousman como la primera película africana de la historia.

14 En N. Frank. Ukadike, Questioning African Cinema. Conversations with Filmmakers, Minneapolis, University of Minnesota Press, 2002, p. 65. 
ulate and socially committed cinema represented by directors was simply too «Western» for these critics ${ }^{15}$.

En tercer lugar, el autor, a través de sus películas, se ocupa de temas incómodos; defiende a ultranza a los damnés de la terre; se niega a imitar los lenguajes y tradiciones artísticos occidentales; critica las condiciones de desigualdad y el olvido de las historias de mujeres y otros «olvidados»; pugna por la restitución de la subjetividad y la agencia de los sujetos africanos y lucha contra la alienación. Todo estos aspectos lo han singularizado como un «director político», con los efectos negativos que acarrea tal etiqueta. A esto se unen sus declaraciones en prensa y apariciones en encuentros especializados, en los cuales que se ha mantenido firme a lo largo de los ańos. Centrándose en sus temas y mensajes contundentes, incómodos en la actual escena neocapitalista, laxa en ideas político-sociales del cine global, los críticos especializados en cines africanos han obviado su experimentación formal cegados por los adjetivos ideológicos. Esto se debe, en buena medida, a la escasa formación cinematográfica de muchos de ellos al provenir de los estudios literarios o culturales, dos áreas de estudio preeminentes en la Academia norteamericana y anglosajona y ámbito en la que centraré mi estudio por sus implicaciones perversas.

Paradójicamente, las razones por las que Med Hondo ha sido minimizado o simplificado en la historia de la crítica especializada en los cines africanos (por las peculiaridades de su persona y obra), son las mismas que lo deben situar a nivel de igualdad con cineastas de otras latitudes en la historia del cine universal.

Director y activista, revolucionario en temas, técnica y forma, Med Hondo sólo se puede igualar al senegalés Sembène Ousman en el grupo de directores pioneros de los cines africanos subsaharianos por la calidad y variedad de sus películas, su estilo personal, la fuerza y claridad de su mensaje. Es por ello que se le ha tachado de «occidental» en más de una ocasión, cuando querían parecer decir, en realidad, «director con calidad técnica y formal». Suya es una filmografía que no rehúye tocar los aspectos más complicados de la realidad contemporánea, sino que los vivisecciona y organiza para el espectador con una lucidez que le ha hecho llevar la delantera en temas y tratamiento a tantos otros directores. En su haber quedan una de las más notables épicas históricas africana -Sarraounia-, definida por el crítico e historiador de cine africano Frank Ukadike como un «hito del cine africano; ambiciosa por su inventiva, profesionalismo y dedicación ${ }^{16}$; una de las películas africanas de mayor experimentación formal -Soleil Ô-; el insólito musical histórico sobre las Indias Occidentales - West Indies-, o el primer thriller de investigación

15 David Murphy: «Africans filming Africa: questioning theories of an authentic African cinema». En Journal of African Cultural Studies. Volumen 13, Número 2, Diciembre 2000, pp. 240-241.

16 En N. Frank Ukadike, Black African Cinema, Bekeley, University of California Press, 1994, pp. 290-294. 
realizado por un africano en suelo francés - Lumière noire-, a través del cual presentaría el drama de la expulsión real de 101 malienses. Med Hondo, sin duda el director revolucionario africano y negro más genuino, ha seguido tanto la agenda del Tercer Cine como la del Segundo Cine, oponiéndose a encorsetamientos de la crítica tradicional y elevándose como un autor único que merece mención y análisis aparte.

\section{UNA HISTORIA CRÍTICA DE LOS ESTUDIOS DE CINE AFRICANOS}

Desde los inicios de los estudios africanos ligados al cine, la diferencia entre la crítica y el examen teórico-histórico ha sido mal comprendida o poco respetada, y la influencia de las «modas» académicas demasiado marcada en las publicaciones académicas. Frente a la mayor separación en la investigación de otros cines entre crítica y análisis teórico, el nacimiento tardío de los cines africanos en los combativos años 60 explica en parte la falta de precisión o de rigor analítico. Con el objetivo en su agenda de devolver la «voz y la imagen» a un continente alienado, profesores africanos y occidentales (prioritariamente) en las universidades de los EE. UU. se lanzaron a escribir sobre el «cine africano» acentuando aspectos de oposición y lucha en sus narrativas. A su manera, continuaban desde las trincheras de las aulas la línea marcada por las naciones del continente que, en las décadas de los 50 y 60, se habían independizado de los poderes coloniales. Seguían de cerca las películas de Sembène Ousmane y otros pioneros, los cuales entendían el medio como un arma de educación y de liberación en la línea del Tercer Cine.

Las primeras publicaciones sobre los cines africanos en los EE. UU. datan del inicio de los años 90, momento de afianzamiento de los estudios culturales, en un ambiente de cuestionamiento generalizado en los estudios de cine de las Grandes Teorías (historiografía, realismo y formalismo) por una miríada de teorías o metodologías. Los estudios culturales, poscoloniales y de género, el psicoanálisis, el estructuralismo y la postmodernidad serían consideradas lecturas idóneas para los estudios de los cines de África por unos académicos formados en los ámbitos literarios que veían natural su desembocadura en los estudios culturales.

Urgía reconstruir la Historia, y en ello se aplicaron los estudiosos en sus obras iniciales, con un sesgo político progresista y de oposición usando unas narrativas históricas que agrupaban de manera sencilla cinematografías, películas y autores por temas y orientación ideológica progresista. Saltándose los análisis formales y aquellos que situasen a los cines africanos a escala global, se pasaría rápidamente a lecturas concretas psicoanalíticas, postcoloniales, de género y de la postmodernidad basadas en el mismo corpus de películas. Esta peculiaridad de los estudios de cine africanos se debe en buena medida a la formación literaria de los investigadores, incapaces de comprender en el contexto cinematográfico internacional el fenómeno que estaban estudiando, despreciando el valor de 
la forma fílmica y desestimando las peculiaridades del medio. Se podría estar escribiendo sobre una novela, un cuadro, una obra de teatro o un filme, que el lector no se daría cuenta de la diferencia ante las críticas de las películas individuales. En el año 2014, a pesar de un aumento exponencial en las investigaciones de casos concretos más complejos, seguimos careciendo de una verdadera investigación que revise y complemente datos históricos y revise paradigmas, ofreciendo lecturas en las que se empleen herramientas de análisis de tradiciones diversas dependiendo del objeto de estudio. Reexaminar el tratamiento y el espacio que ha ocupado Med Hondo en los estudios de los cines africanos nos servirá para exponer los vacíos y ansiedades, obsesiones y tendencias de la crítica y la teoría africana desde su aparición a principios de los años 90 hasta la actualidad.

El artículo de Josef Gugler «Fiction, Fact, and the Critic's Responsability: Camp the Thiaroye, Yaaba, and The Gods Must Be Crazys ${ }^{17}$ incluido en el volumen de Françoise Pfaff Focus on African Films me sirve de arranque para este recorrido por la historia del discurso teórico-crítico de los cines de África ligados a Med Hondo ${ }^{18}$. En el año 2004, recuerda Gugler «the power of fiction in shaping ideas and influencing action». Como hemos señalado anteriormente, por la falta de acceso a las fuentes directas (las películas), el discurso de los especialistas se ha ido adaptando al ritmo de las modas dictadas por la Academia. Esto ha afectado de manera perversa a la recepción de las películas africanas y muy directamente a la filmografía de Med Hondo y a su imagen personal. Por ello, además del repetido poder del cine en la creación de un imaginario y manera de comprender el mundo, la capacidad de influenciar del discurso de ficción se ha de hacer extensible a los discursos producidos por la crítica y la teoría sobre los cines africanos. Estos se revelarán, en el caso de Med Hondo, más poderosos que las propias películas de las que se ocupan.

Por orden cronológico, el primer estudioso del cine africano ${ }^{19}$ que dedica parte de sus páginas al director mauritano es Manthia Diawara en su inaugural African Cinema. Politics \& Culture $(1992)^{20}$. Obra organizada por áreas de influencia colonial (África anglófona, francófona y lusófona), estudia de manera prioritaria la producción y distri-

17 En Françoise Pfaff (ed.), Focus on African Films, Bloomington e Indianápolis, Indiana University Press, 2004, pp. 69-85.

18 No por casualidad está publicado en el libro de Pfaff a continuación del estupendo ejercicio de erudición y perspicacia de Mbye Cham sobre las tendencias del cine histórico contemporáneo en África, escrito al que volveremos por su análisis de la película épica de Med Hondo Sarraounia (1986).

19 El debate acerca de la terminología empleada para delimitar el campo de estudio ha ido cambiando con autores que defienden el uso del singular (cine africano) frente a los que consideramos más oportuno emplear el plural (cines africanos, cines de África) al explicitar la naturaleza múltiple de estas cinematografías.

20 Manthia Diawara, en esta obra fundacional, se hace eco de la polémica terminológica apenas apuntada. El título singular "African Cinema» se verá modificado casi veinte años más tarde por el inocuo «African Film». 
bución de las películas desde una perspectiva histórica. Centrándose en el estudio de un número limitado de películas (Sembène Ousmane, Souleymane Cissé, y otros) Diawara realiza un primer acercamiento a la estética fílmica y de los temas de las primeras décadas de vida de los cines africanos. De las obras de Med Hondo, tan solo Sarraounia merece mención en el capítulo final «African Cinema Today» bajo el epígrafe "Colonial Confrontation» en alusión al papel de las mujeres en la lucha anticolonial del siglo XIX y en el mantenimiento de una cultura precolonial dinámica en África ${ }^{21}$. En esta sección, el autor se concentra en fijar ejes temáticos y narrativos, sin cuidar apenas aspectos técnico-formales. Los otros dos epígrafes del mismo capítulo -«Social Realist Narratives» y "The Return to the Source»- van en la similar dirección, estableciendo un análisis temático, histórico y social que se convertirá en canónico en el área. La obra de Manthia tuvo la virtud de presentar los cines africanos de manera contextualizada y estructurada, pero la falta de interés en los valores estético-formales de las obras empujó por vez primera a Med Hondo a un inmerecido segundo plano.

Contrarrestando este injustificado olvido, dos años después -1994- ve la luz la excepcional y aislada monografía de Ibrahima Signaté sobre Med Hondo: Med Hondo. Un cinéaste rebelle editado por Présence africaine y que sigue siendo hoy día el documento con mayor número de información sobre la obra, la filosofía, las ideas y la historia personal del autor. Sirviéndose del formato de la conversación, Signaté recoge las declaraciones sobre la estética y filosofía de Med Hondo, así como anécdotas y datos concretos sobre la producción de sus películas que se repetirán, sin apenas revisión, en estudios parciales en fechas posteriores. En el prefacio, Signaté afirma:

Le cinéma est pour lui plus qu'un art de vivre, un moyen pour l'irruption de l'Afrique au monde, par l'affirmation et l'exaltation de sa personnalité ${ }^{22}$.

Como hemos visto, el cine de Hondo habla por sí mismo y se enfrenta de manera directa al mimetismo de las películas de Occidente. Con un estilo, temas y mensaje reconocibles por su especificidad, el autor se distingue del resto de directores africanos. Sin embargo, la claridad y firmeza en sus propuestas políticas se han manifestado negativas para la difusión y recepción de sus películas. Además del adjetivo «rebelde» en el subtítulo, la monografía de Signaté incluye capítulos críticos sobre la emigración, el papel de la mujer, el tribalismo, la unidad africana o el integrismo, todos ellos temas habitualmente tratados en sus obras y que serán recuperados como epígrafes sobre los cines africanos en obras críticas más tardías. A pesar de la mala prensa que el término

21 En Manthia Diawara, African Cinema. Politics \& Culture, Bloomington e Indianápolis, Indiana University Press, 1992, pp. 153-154.

22 En Ibrahima Signaté. Med Hondo. Un cinéaste rebelle, París y Dakar, Présence africaine, 1994, p. 6 del Prefacio. 
empezaba a tener a principios de los años 90, se incluye un capítulo sobre el marxismo, donde el autor expresa de manera calibrada sus ideas:

Le marxisme n'est pas une recette de cuisine. Il fait appel à l'intelligence de l'homme. Il aurait dû être un guide pour l'action, donc adapté à chaque situation, et non un dogme. Nous autres, Africains, aimons trop hélas ingurgiter les théories toutes faites (...) le marxisme comme un outil de réflexion sur la théorie économique et politique ${ }^{23}$.

Para Hondo, el marxismo es una herramienta de reflexión que ha de llevar a los pensadores africanos a «rompre avec le mimétisme pour penser par nous-mêmes et pour nous-mêmes ${ }^{24}$. Si bien éste es uno de los objetivos del autor, el verbalizar tales opiniones ha sido a la larga contraproducente puesto que ciertos estudiosos se han escudado en sus ideas políticas para no profundizar en su obra.

En el año 2000, el crítico de cine Oliver Barlet editaba en inglés su obra Les cinémas d'Afrique noire. Le regard en question. Publicada originariamente en francés cuatro años antes y ganadora del premio Art et Essai du CNC en 1997, se convirtió pronto en libro de referencia para adentrarse en el panorama de los cines africanos. En la línea habitual del editor de Africultures, en este ensayo de aspiraciones humanistas, revisado y actualizado en su versión inglesa, Barlet plantea cuestiones sobre la alteridad, el problema de la recepción y la crítica occidentales, y ofrece una explicación amplia sobre los contextos económicos y sociales de producción del cine y de la televisión africanos. Sirviéndose de entrevistas y charlas mantenidas durante ańos con los propios directores, y de críticas de estilo periodístico y cinéfilo, Med Hondo aparece en diversas secciones de la obra a través del estudio de películas concretas y ligado a problemas de producción, distribución y exhibición de las mismas. Su primera aparición es rotunda, criticando el cine de Jean Rouch y haciéndose eco del comentario de Sembène Ousmane al paternalismo de Rouch años antes. Hondo exclama sobre las películas de Rouch:

In all his films he brings out an alleged African cultural specificity, which makes us appear ridiculous. He is a man who has always regarded us, deep down, as insects ${ }^{25}$.

Barlet presenta a Med Hondo como un hombre combativo y sin pelos en la lengua que critica el exotismo occidental y la «especificidad africana» para, en las secciones

23 En Ibrahima Signaté. Med Hondo. Un cinéaste rebelle, París y Dakar, Présence africaine, 1994, p. 89.

24 Ibid., p. 90.

25 En Olivier Barlet, African Cinemas. Decolonizing the Gaze, Zed Books, Londres y Nueva York, 2000, p. 8. 
siguientes, traer a colación sus películas. Se invoca Soleil Ô para poner en evidencia la ambigüedad de los discursos relacionados con los juicios políticos de izquierdas en el apartado titulado "Lucha de clases sin pancartas»; a Sarraounia y West Indies al tratar del papel del cine en la recuperación de una historia silenciada y, en concreto, al aludir a las historias de figuras históricas positivas africanas en la sección «Faraones negros»; y a Watani, un monde sans mal bajo el epígrafe «Leyenda: ¿un camino errado?», donde se recogen unas frases de Hondo apuntando los paralelismos y relaciones entre seres humanos independientemente del su cultura de origen, sugiriendo la necesidad de Occidente de ser receptivo al otro y respondiendo, no cabe duda, a la condena económica sufrida por obligarle a incluir en Watani un aviso sobre el nivel de violencia cuando se proyectó en salas comerciales francesas. El tema del racismo urbano occidental hizo mella en las instituciones gubernamentales impulsando esta acción censora.

Cuando Barlet estudia el uso de la música y polemiza sobre las lenguas autóctonas o coloniales en los filmes, Hondo es llamado de nuevo a la palestra con una canción de Soleil Ô y con la defensa que hace del uso del francés, un idioma que ha adquirido con esfuerzo y que es su lengua diaria, sin dejar de precisar: «Even though I am a user of French, I don't feel any calling to become an activist for the French language» ${ }^{26}$. Las lenguas son propiedad de todos los que las emplean, sin privilegios de autoridad basados en conceptos raciales o de autenticidad. Evidentemente, una película en francés alcanza potencialmente a un público mayor, sin embargo, aunque este idioma predomina por verosimilitud en sus filmes situados en Europa, Med Hondo usa otras lenguas. En el caso de Sarraounia recurrió al diula y al fula además de al francés por fidelidad histórica.

En la última sección del libro de Barlet, dedicada a las vicisitudes y experiencias de los directores africanos a la hora de ver realizadas y distribuidas sus películas, el trabajo de Med Hondo como doblador de voces de afroamericanos (su medio principal de subsistencia) ejemplifica los escollos de muchos de los directores africanos. Otros ejemplos similares son el rodaje de Soleil $\hat{O}$ durante sus fines de semana libres o las repetidas trabas y problemas para ver realizada Sarraounia. Los problemas con la censura, las dificultades de financiación y las complicaciones del rodaje han provocado filmografías africanas escuálidas, al tener que dedicar los directores interminables años para que una película sea proyectada.

Desde Gran Bretaña, ese mismo año Junne Givanni editaba el volumen Symbolic Narratives/African Cinema (2000). Med Hondo es definido, una vez más, como abiertamente político en la contribución de Férid Boughedir «African Cinema and Ideology: Tendencies and Revolution». Sorprende que, en una obra tan extensa, sólo salga a relucir en esta sección y en la de Clyde Taylor «Searching for the Postmodern in African

26 En Olivier Barlet, African Cinemas. Decolonizing the Gaze, Zed Books, Londres y Nueva York, 2000, p. 197. 
Cinema», en la que se le define como "postmoderno" por su forma, sin entrar en más detalles.

No es de extrañar que el militante Boughedir siga en la línea de la monografía de Ibrahima Signaté, utilizando el epíteto de «revolucionario» para Med Hondo. En su artículo, el director, crítico y profesor tunecino establece viejas y nuevas tendencias de los cines africanos, calificando los filmes del mauritano dentro de la tendencia que él llama política (o socio-política), caracterizada por atender a temas como la lucha contra el colonialismo y la historia africana recuperada desde una ideología progresista, empleando el pasado para hablar sobre el presente y aventurar el futuro. Las distintas censuras ante las que se viene enfrentando también merecen la atención de Boughedir. De nuevo, vemos cómo se repiten las mismas afirmaciones sobre el autor regresando a lo temático, político e ideológico sin preocuparse por lo formal y estético.

La novedad de la aportación de Clyde Taylor reside en el recurso a la postmodernidad para adentrarse en las obras de un manojo de directores africanos. Con este movimiento, pretende situarlos en el «juego global» del cine contemporáneo internacional basándose en sus narrativas fragmentarias y no lineales aunque, al hacerlo, desatiende un análisis cercano de las obras de Med Hondo, las cuales son claramente «modernas» por sus mensajes y técnicas cinematográficas, además de herederas de tradiciones culturales, teóricas y artísticas africanas en sus narrativas y temática.

\section{Africa Shoots Back. Narrative Perspectives in Sub-Saharan Francophone African Film} (2003) de Melissa Thackway propone una lectura más comprensiva del lugar de Med Hondo. En este trabajo sobre la producción cinematográfica francófona subsahariana la autora dedica en la introducción un espacio a Hondo:

In the late Sixties and Seventies, several other filmmaking trends and styles began to emerge. In his first film Soleil Ô (1969), the French-based, Mauritanian filmmaker Med Hondo adopted a radically politicized and experimental style. This blending of genres and registers is clearly marked by both the non-linear, fragmentary constructions found the West African oral traditions, and by the deconstructionism of Brechtian theatre. Hondo's generic blending and politically strident voice still find echo in the later works of other politically vociferous filmmakers, such as Cameroonian Jean-Marie Teno, who also combines formal experimentation and overt political reflection ${ }^{27}$.

El párrafo es una recapitulación sopesada de enunciaciones sobre el director hechas con anterioridad. La filiación que se establece entre Hondo y el documentalista

27 En Melissa Thackway, Africa Shoots Back. Alternative Perspectives in Sub-Saharan Francophone African Cinema, Bloomington y Oxford, Indiana University Press y James Currey, 2003, pp. 9-10. 
Jean-Marie Teno resulta novedosa, sugiriendo una tendencia experimental y política dentro de los cines africanos, en la que la experimentación formal y la reflexión política son aspectos comunes a ambos autores. Más adelante, Thackway critica los paradigmas críticos occidentales en relación a los cines africanos. Comenta que, estableciendo al cine Occidental como normativo y al resto como "counter-cinemas", se ha impedido que obras no occidentales sean calificadas de vanguardistas o experimentales. La proclamación de "godardiano" de Soleil Ô (cuando, en realidad, fue realizada antes de los filmes experimentales del francés) y de deconstruccionismo brechtiano, olvidando que la base son las tradiciones orales, se explica por esta propensión occidental de apropiación y negación de lo «otro».

En los capítulos que ahondan sobre la creación de la memoria a través de unas narrativas que completen, critiquen y desafíen a la Historia occidental hegemónica, se recuerdan las censuras a Sarraounia por atreverse a abordar unos hechos negativos para la crónica oficial gala. Tampoco podían faltar Soleil Ô y Watani en el capítulo «Filming the Inmigrant Experience. Francophone African cinema in Europe». Casi dos décadas después de su proyección en Cannes, Melissa Thackway realiza el primer análisis pormenorizado de Soleil $\hat{O}$, definido como el "first radically political 'film essay'»" africano, aserción que desarrolla en una nota a pie de página:

The film's closing title, "To be continued...», confers an openness on the film that suggests that Hondo sees it as a part of a continuing debate, thereby confirming the idea that the film can be seen as a dialogic essay ${ }^{29}$.

La evolución del cine político de los pioneros a uno más globalizado de historias menores y géneros populares por las generaciones jóvenes, se puede observar según Thackway en Lumière Noire, donde Hondo «abandons his more typically experimental filmmaking style in order to adhere to the conventions of the French polan ${ }^{30}$. Al hacer esta afirmación se está olvidando de Sarraounia, el que se podría considerar el «más clásico» de sus filmes por la narrativa, técnica, género y estilo. Habría sido más apropiado reiterar la diversidad de cada una de sus películas, las cuales encuentran su forma en el mensaje a transmitir y en las ansias de probar con diversas formas, géneros y estilos cinematográficos y artísticos. Sin embargo, al querer establecer tendencias generales en una línea evolutiva, Thackway ha de ocultar ciertas verdades históricas que no se amoldan a su hipótesis.

$\overline{28}$ En Melissa Thackway, Africa Shoots Back. Alternative Perspectives in Sub-Saharan Francophone African Cinema, Bloomington y Oxford, Indiana University Press y James Currey, 2003, p. 127.

29 Ibid., p. 127.

30 Ibid., p. 139. 
Med Hondo es referente obligado cuando la autora escribe acerca del racismo, los estereotipos y el exotismo en las relaciones sexuales interraciales (escena de Soleil $\hat{O}^{31}$ ) y sobre los problemas de la censura (negación de permisos de rodaje en el aeropuerto para Lumière Noire ${ }^{32}$ ). En el último capítulo «African Women \& Film», la reina de los Aznas -Sarraounia- ejemplifica para la autora un icono mítico de lucha anticolonial y una mujer que ya no es pasiva, sino que "clearly moves away from the image of the passive, subjugated female and stresses the instrumental role of women in the resistance struggle» ${ }^{33}$. Sin embargo, todavía no es una mujer de carne y hueso sino que está al servicio de una causa mayor. Tendremos que esperar a la obra Fatima, l'Algérienne de Dakar para que esto cambie.

Estos apuntes sobre Sarraounia serán ampliados por Mbye Cham en su contribución sobre «Historia y cine en África» ${ }^{34}$ incluido en el volumen editado por François Pfaff en 2004. Sin lugar a dudas, es el suyo el análisis más detallado, comprensivo y acertado que se había hecho hasta la fecha sobre una película de Med Hondo. Para estudiar las corrientes y tendencias de las películas africanas contemporáneas sobre la historia, el teórico y crítico escribe de una manera erudita a la vez que cercana, en la que demuestra un conocimiento exhaustivo de la producción contemporánea, del contexto histórico y de las peculiaridades de cada una de las películas. Elige como caso paradigmático a Sarraounia, filme sobresaliente por su tema, calidad técnica y formal y por explicitar la complicada relación histórica de Francia con sus excolonias a través del cine. Med Hondo hablaba así a Ukadike sobre la película: «There is an obligation to make such historical films, because the truth inherent in the story» ${ }^{35}$. Tal como apuntamos brevemente arriba, tras siete años de pugnas lidiando con condiciones de financiación y de producción horrendas, y ayudado por el líder burkinabé Thomas Sankara, Med Hondo pudo finalizar su cuarto largometraje. Basada en la novela homónima de su amigo, el escritor de Níger Abdoulaye Mamani, Sarraounia cuenta, a través de las gestas de la reina de los Azna, el encuentro de los pueblos africanos con los colonizadores franceses en África occidental a finales del siglo XIX. El ingente trabajo de documentación previo a través de narraciones orales y textos escritos para el libro y la película, es visible en las localizaciones, en la minuciosa reconstrucción histórica de vestimentas, peinados, herramientas y espacios como el palacio, así como en la fidelidad de los hechos narrados. Ganadora

31 En Melissa Thackway, Africa Shoots Back. Alternative Perspectives in Sub-Saharan Francophone African Cinema, Bloomington y Oxford, Indiana University Press y James Currey, 2003, p. 141.

32 Ibid., pp. 145-146.

33 Ibid., p.174.

34 Mbye Cham «Film and History in Africa: A Critical Survey on Current Trends and Tendencies», en Françoise Pfaff. Focus on African Films, Bloomington e Indianápolis, Indiana University Press, 2004, pp. 48-68.

35 En N. Frank Ukadike (ed.), Questioning African Cinema. Conversations with Filmmakers, Minneapolis, University of Minnesota Press, 2002, p. 68. 
del máximo premio en FESPACO en 1987, es una de las primeras y más conseguidas épicas africanas llevadas al cine, en la que Hondo evita la nostalgia y la glorificación de una gesta pasada. Parafraseando a Mbye Cham:

Sarraounia is a song in praise of dignity, determination, difference, and devotion to ideals of freedom, justice, tolerance, understanding, and love. It is also a study on the mentality of terror as well as a lament about closed minds and their dehumanizing consequences $^{36}$.

El análisis histórico, los datos sobre aspectos de la producción, financiación y distribución de la película, y su ubicación dentro de la filmografía de Hondo componen un estudio todavía no superado. Diez años después de su publicación, coincido plenamente con las conclusiones de Mbye Cham:

Sarraounia relates parallel narratives of struggle, sacrifice, determination, and vision -one historical and the other contemporary. The conflation of the past and the present in the story of the legendary Queen Sarraounia and in the story of the production, distribution, and exhibition of the finished film itself is a revealing and instructive aspect of African creativity and resilience ${ }^{37}$.

Sin duda, esta brillante crítica fue una de las razones que llevarían a Murphy y Williams a centrarse en Soleil Ô en su Postocolonial African Cinema. Ten Directors (2007) y a pasar de puntillas por Sarraounia. Este libro se centra en diez de los directores africanos más notables de la época postcolonial africana, la cual se extiende de los ańos 50 hasta nuestros días. Med Hondo aparece en tercer lugar tras el egipcio Youseef Chahine y el senegalés Med Hondo, siendo Djibril Diop Mambety, Souleymane Cissé, Flora Gomes, Idrissa Ouédraogo, Moufida Tatli, Jean-Pierre Bekolo y Darrell James Roodt quienes completan el elenco.

Postcolonial African Cinema. Ten Directors es a día de hoy uno de los intentos más calibrados de estudiar en profundidad un grupo selecto de directores africanos, siendo de interés tanto para especialistas como para el público general. Su fluido uso de disciplinas diversas (los estudios cinematográficos, los estudios culturales africanos y los estudios postcoloniales) sirven para analizar tanto películas individuales como filmografías completas de los autores escogidos. En vez de adaptar las obras al andamiaje teórico (algo habitual en obras anteriores), el análisis de filmes concretos obliga a reflexionar de

36 En Mbye Cham «Film and History in Africa: A Critical Survey on Current Trends and Tendencies», en Françoise Pfaff. Focus on African Films, Bloomington e Indianápolis, Indiana University Press, 2004, p. 64.

37 Ibid., p. 66. 
manera más amplia. Cada capítulo se dedica a un autor y sigue el mismo esquema: tras una introducción general se realizan análisis concretos de obras, desde los que van surgiendo importantes cuestiones teoréticas que ofrecen una perspectiva amplia de la realidad cinematográfica africana postcolonial. El capítulo dedicado a Med Hondo empieza registrando el desconocimiento de aspectos de su vida, considerados como determinantes por Murphy y Williams para comprender su obra:

\begin{abstract}
Although the Mauritanian director Med Hondo is acknowledged as one of the great postcolonial chroniclers of the lives of the unrecognized and unrepresented masses in the various waves of the African diaspora, his own life and its relevance for his filmmaking is less acknowledged ${ }^{38}$.
\end{abstract}

A partir de ahí se hará un repaso a sus orígenes, etapa formativa y emigración a Francia, aspectos que han influido en los temas, filosofía, estética y forma de sus obras, en los problemas de censura y financiación y en su incomprensión. Me interesan las siguientes palabras:

\title{
... he frequently insists on doing what other filmmakers do not, or will not -for what- ever reason- do. Constantly working against the grain of dominant cultural practice -even if it is dominant only within the relatively restricted field of African or postcolonial filmmaking - is almost bound to make him a controversial figure ${ }^{39}$. (Cursivas mías).
}

Med Hondo ha escapado de los temas «suaves» de otros directores y ha luchado contra la mediocridad técnica y formal imperante en muchas producciones africanas usando la experimentación y la calidad técnica. La frase entre corchetes es de gran interés para este artículo, ya que afirma el campo cerrado que los estudios africanos y postcoloniales representan en los estudios cinematográficos globales. El director mauritano ha de salirse de estos círculos para ser comprendido y examinado en su justa medida. Sin embargo, en un momento histórico en el que la producción audiovisual es ingente, los juicios de los especialistas en cinematografías minoritarias se mantienen como el punto de partida para que otros estudiosos se acerquen a ellos. El análisis de Sarraounia de Cham y el de Soleil Ô del tándem Murphy-Williams van en esta dirección. «Hondo and Fanon: the dialectics of liberation» encabeza el estudio de los británicos presentándonos su hipótesis: del análisis de Soleil $\hat{O}$, de la vida y del resto de la filmografía de Hondo se puede aseverar que es "arguably the most Fanonian of African films» ${ }^{40}$, hallándose paralelismos diáfanos entre las obras e ideas del director y del pensador Frantz Fanon. Por

38 En David Murphy y Patrick Williams, Postcolonial African Cinema. Ten directors, Manchester, Manchester University Press, 2007, p. 71.

39 Ibid., p. 77.

40 Ibid., p. 79. 
supuesto, esta hipótesis es relevante para un volumen donde los estudios postcoloniales son prioritarios, lo cual no impide examinar la obra en un futuro haciendo uso de otras disciplinas.

Entre los últimos manuales dedicados a las películas, autores y cinematografías africanos (Olivier Barlet: 2012 ${ }^{41}$, Alexie Tcheuyap: 2011 ${ }^{42}$, y Manthia Diawara: 2010 ${ }^{43}$ ) Med Hondo apenas aparece. Los autores, obsesionados por dejar constancia de nuevas tendencias y cineastas, niegan el componente abiertamente político de las primeras realizaciones. Esta actitud negadora de lo anterior y una valoración excesiva de lo nuevo podría tener algo de sentido para un crítico y periodista como Barlet, pero resulta más sospechosa en los casos de Diawara y Tcheuyap, profesores y académicos. En un sentido opuesto está el comentario de Akinwumi Adesokan de que los discursos anti-coloniales de Sembène y Hondo ayudaron a la vida del cine en África:

$\ldots$ it is now clear that in their preoccupation with the politics of representation involved in anticolonial discourse, the early films—such as Med Hondo's Soleil $\hat{O}$ and Sembene's Emitaï-were paradoxically enabling the cinema’s external condition of possibility ${ }^{44}$.

Sin embargo, Adesokan no ahondará en esta idea. La reflexión apresurada y reactiva de los críticos se confunde con la sopesada y distante en el tiempo de los teóricos e historiadores. Extraña que en otras cinematografías se haya abandonado la necesidad de realizar grandes manuales, compendios u obras aglutinadoras, siendo la tendencia habitual los análisis parciales y minuciosos. En los estudios canónicos de los cines africanos se ha dejado por el camino la necesaria revisión de grandes autores, desvelando una falta de interés por la historiografía (base de otros análisis posteriores) y, en el fondo, una creencia en que las primeras películas no eran de suficiente calidad ya que (algo repetido en los artículos relacionados con África) «su momento de esplendor está por llegar» ${ }^{45}$. La respuesta de la crítica, no siempre apropiada, ha de ser contrarrestada por la de historiadores y teóricos, los cuales ofrecen lecturas adecuadas para aquellos que no se ven apremiados por la inmediatez periodística.

Para recapitular, las ansias de mapear lo nuevo y de escapar del paradigma de lo político ha impedido un trabajo escrupuloso de autores como Med Hondo, los cuales

41 Les cinemas d'Afrique des années 2000. Perspectives critiques, París, L'Harmattan, 2012.

42 Postnationalist African Cinemas, Manchester, Manchester University Press, 2011.

43 African Film. New Forms of Aesthetics and Politics. Munich, Prestel, 2010.

44 En Akinwumi Adesokan, Postcolonial Artists and Global Aesthetics. Bloomington \& Indianápolis, Indiana University Press, 2011, p. 131.

45 En este sentido véanse las reflexiones sobre la calidad en ascenso de las películas de Nollywood, con el término recientemente acuñado de «New Nollywood» de claros ecos vanguardistas. 
meritan ser situados en una perspectiva más amplia. Para sacar a los directores africanos del gueto de los estudios africanos y de los festivales y encuentros especializados, es necesario integrarlos en otras publicaciones y espacios de difusión y exhibición. Las posibilidades creadas por la tecnología digital y las plataformas de internet permitirán en el siglo XXI incluir a autores africanos a nivel de igualdad con sus pares internacionales. Para ello, es preciso que sean explicados y difundidos por la teoría y la crítica cinematográfica desde disciplinas diversas. Fuera de las publicaciones de los estudios africanos, encontramos una interesante $y$, desde mi punto de vista, más apropiada inclusión de Med Hondo. Se trata del capítulo de Philip Rosen «Notes on Art Cinema and the Emergence of Sub-Saharan Film» en Global Art Cinema: New Theories and Histories, editado por Rosalind Galt y Karl Schoonover $(2010)^{46}$. En un libro dedicado al cine arte global, se atestigua la relación directa de Med Hondo con el teatro, sin estigmatizarlo como un director político y rebelde sino situándolo como un autor situado entre el Tercer, el Segundo y el Primer cine. Seguir la propuesta de Rachel Gabara para Abderrahmane Sissako en el mismo volumen como un director africano a caballo entre distintos Cines, servirá para ahondar en el conocimiento de Med Hondo en los años venideros.

\section{CONCLUSIÓN}

La historia del tratamiento de Med Hondo por la crítica y la teoría especializada demuestra cómo los análisis ligados a los cines africanos han sido dúctiles a los devaneos de las modas de la crítica y la teoría. Al toparse con una obra compleja como la del director mauritano, los problemas surgen y se actualizan.

En los últimos ańos, la crítica africana se ha obsesionado por de salir del cine arte o Segundo Cine, un cine centrado en la figura del autor y en el conocimiento de la estética y de tradiciones artísticas diversas. El nacimiento y establecimiento de la industria del cine de vídeo de Nigeria (Nollywood) se lee como la llegada de «un cine del pueblo y para el pueblo» llamado a acabar con el cine elitista de autor patrocinado por Occidente y hecho a imagen y semejante de sus realizaciones, con un toque exótico para teñirlo de autenticidad. Tras una época de cine combativo y revolucionario, ha llegado la hora del cine popular comercial (oímos por doquier). Estamos, una vez más, dejándonos llevar por el vicio de los conceptos duales y simplificados que no ayudan al conocimiento y difusión de autores, obras y cinematografías africanos, sino que los aíslan y encasillan. En el siglo XXI deberíamos estar aplaudiendo la variedad y diversidad de propuestas, autores, temáticas y géneros que vienen de África y la diáspora.

46 Rosalind Galt y Carl Schoonover, Global Art Cinema: New Theories and Histories, Oxford, Oxford University Press, 2010. 
Tal y como hemos visto, la obra de Med Hondo es paradigmática de la necesidad de luchar contra la "historia única" a través de las historias narradas y representadas, desde la propia praxis artística y en su concepción ética y filosófica como hombre público. El mauritano ha construido con su filmografía una historia opuesta y complementaria a la de los discursos oficiales occidentales y a la de sus semejantes africanos. Entenderlo y devolverlo al lugar que merece es un acto de justicia que obligará a utilizar todo el andamiaje teórico a disposición del cine como lenguaje artístico para ser comprendido.

La actualidad de su filmografía se demuestra en parte por la incapacidad de ser subsumido por el discurso oficial y canónico. Empujando los límites conceptuales de los análisis estético-formales, históricos y autorales, impidiendo su aprehensión por los dogmas más rancios, la obra de Med Hondo emplaza a un análisis cercano y singular que surge de cada obra y del análisis del autor en su contexto. Debemos huir de generalizaciones e ir al detalle. Enfrentarse a lugares comunes, prejuicios y a la pereza de una crítica que se asienta cómodamente en los últimos paradigmas en boga, siguiendo el ritmo frenético impuesto por la Academia actual, son las exigencias de Med Hondo y de su obra, rica en reflexiones y con una investigación histórica de fuentes contrastadas y autorizadas.

En esta tendencia contemporánea de re-escribir y revisar la historia de los cines en África, se están produciendo pequeños gestos para restituir a Med Hondo al lugar que merece. En la reciente $21^{\mathrm{a}}$ edición del African Film Festival de Nueva York (2014), se ha proyectado Sarraounia en la sesión de clausura en el Lincoln Center. La idea inicial de los organizadores del evento de homenajearlo de manera amplia, con un seminario y la proyección de toda su filmografía, se vio truncada en los últimos momentos a causa del delicado estado de salud del director. Sin poder contar con su presencia, y reconociendo la importancia de "darle la palabra" para no obtener declaraciones derivadas, la proyección de la película y una mesa redonda consecutiva, fueron los actos que rindieron tributo a su carrera y a su labor en aras de la liberación del continente y la igualdad social.

Si bien se ha de seguir luchando contra la imagen y el discurso construido entorno a África durante siglos, Hondo nos recuerda que «... nous n'avons pas été les seuls colonisés du monde» ${ }^{47}$. En esta frase postula de nuevo a favor de la toma de responsabilidad de los hombres y mujeres africanos y del artista y el intelectual a nivel global. Continúa:

... tout est question de responsabilité. Ce qui fait de nous les victimes désignées des Machiavels internationaux. Si nous ne faisons pas preuve d'un plus grand sens de nos responsabilités, nous serons bientôt réduits à n'être que les danseurs du monde, des "tamtameurs ${ }^{48}$.

47 En Ibrahima Singaté, Med Hondo. Un cinéaste rebelle. París y Dakar, Présence africaine, 1994, p. 54.

48 Ibid., p. 52. 
El director mauritano ha sido responsable y congruente en todas sus obras, desde el momento del surgimiento de la idea hasta el debate posterior a la proyección de la película. Su labor de autocrítica constante le llevaría a descartar el rodaje de West Indies en Hollywood porque las exigencias de los agentes americanos implicaban cambios que no estaba dispuesto a realizar. "I told them that I respect their ideas, but that the changes they proposed did not do justice to the actual history of Africa that I was trying to reconstruct» ${ }^{49}$. Para eso, ha buscado dinero de manera independiente: "If I wanted my films to retain the authenticity of history, I had to find money by myself.» Sin embargo, al no dejarse dominar por la industria del cine comercial, sus obras quedarían a la merced de »la pire des censures, la censure économique qui, elle, est imparable contrairement à celle de caractère politique» ${ }^{50}$.

Sus películas se muestran inaprensibles tanto para la crítica especializada africana como para la occidental que, como hemos visto, lo ha incluido de pasada en el movimiento de la Nouvelle Vague francesa. Su obra ejemplifica, por etapas, la problemática, ansiedades y preocupaciones de la crítica de los cines africanos independizándose de tendencias generales. Ha llegado la hora de que un corpus fílmico y un autor de semejante talla obtengan el reconocimiento de cineastas experimentales y abiertamente políticos de otras latitudes. La complejidad de su estilo y su mensaje internacional, humanista y progresista lo han llevado al ostracismo. Cineasta «reactivo», atento a la realidad histórica que le ha tocado vivir, comentaba a Ukadike:

\footnotetext{
The more liberal the French people are, the more I have to be radical. Their systems continue to work against Africans, history, and humanity. [...] If I should lose my dignity and my vision of the world, it means I am done for. Anyone with the privilege today of creating images of Africa must do so with consciousness of the meaning of those images ${ }^{51}$.
}

Para aquellos que no hayan tenido el honor de acercarse a sus películas, estas palabras son una invitación a hacerlo.

49 En Frank Ukadike (ed.), Questioning African Cinema. Conversations with Filmmakers, Minneapolis, University of Minnesota Press, 2002, p. 66.

50 En Ibrahima Singaté, Med Hondo. Un cinéaste rebelle. París y Dakar, Présence africaine, 1994, p. 46.

51 En N. Frank Ukadike (ed.), Questioning African Cinema. Conversations with Filmmakers, Minneapolis, University of Minnesota Press, 2002, p. 66. 


\section{FILMOGRAFÍA DE MED HONDO}

Soleil Ô (1969), 35mm, B/N, ficción experimental. $98 \mathrm{~min}$.

Le Bicots Nègres Vos Voisins (1974), 35mm, color, ficción experimental. 190 min.

Sahel la faim porquoi (1975), 35mm, color, documental, $104 \mathrm{~min}$.

Nous auron toute la mort pour dormir (1977), 35mm, color, documental, 160 $\min$.

West Indies, Les Nègres Marrons de la Liberté (1979), 35mm, color, ficción-experimental, $110 \mathrm{~min}$.

Sarraounia (1986), 35mm, color, ficción, $120 \mathrm{~min}$.

Lumière Noire (1992), 35mm, color, ficción, 105 min.

Watani, un monde sans mal (1998), 35mm, color, ficción, $78 \mathrm{~min}$.

Fatima, l'Algérienne de Dakar (2004), 35mm, color, ficción, 89 min.

\section{BIBLIOGRAFÍA}

Adesokan, Akinwumi, Postcolonial Artists and Global Aesthetics, Bloomington e Indianápolis, Indiana University Press, 2011.

Armes, Roy, African Filmmaking. North and South of the Sahara, Edinburgh, Edinburgh University Press, 2006.

Barlet, Olivier, African Cinemas. Decolonizing the Gaze, Zed Books, Londres y Nueva York, 2000.

Barlet, Olivier, Les cinemas d'Afrique des années 2000. Perspectives critiques, París, L'Harmattan, 2012.

Diawara, Manthia, African Cinema. Politics \& Culture, Bloomington e Indianápolis, Indiana University Press, 1992.

Diawara, Manthia, African Film. New Forms of Aesthetics and Politics, Munich, Prestel, 2010.

Galt, Rosalind y Carl Schoonover, Global Art Cinema: New Theories and Histories, Oxford, Oxford University Press, 2010. 
Givanni, June (ed.), Symbolic Narratives/African Cinema. Audiences, Theory and the Moving Image, Londres, BFI, 2001.

Murphy, David, "Africans filming Africa: questioning theories of an authentic African cinema». En Journal of African Cultural Studies. Volumen 13, Número 2, Diciembre 2000, pp. 239-249.

Murphy, David y Patrick Williams, Postcolonial African Cinema. Ten directors, Manchester, Manchester University Press, 2007.

Pfaff, Françoise (ed.), Focus on African Films, Bloomington e Indianápolis, Indiana University Press, 2004.

Pines, Jim y Paul Willemen (ed.), Questions of Third Cinema, Londres, British Film Institute, 1989.

Signaté, Ibrahima, Med Hondo. Un cinéaste rebelle, París y Dakar, Présence africaine, 1994.

Tcheuyap, Alexie, Postnationalist African Cinemas, Manchester, Manchester University Press, 2011.

Thackway, Melissa, Africa Shoots Back. Alternative Perspectives in Sub-Saharan Francophone African Cinema, Bloomington y Oxford, Indiana University Press y James Currey, 2003.

Ukadike, N. Frank, Black African Cinema, Bekeley, University of California Press, 1994.

Ukadike, N. Frank, Questioning African Cinema. Conversations with Filmmakers, Minneapolis, University of Minnesota Press, 2002.

Ukadike, N. Frank, Critical Approaches to African Cinema Discourse, Plymouth, Lexington Books, 2014. 
Página intencionadamente en blanco 